\title{
Processing of Superfine and Ultrafine Phosphate of a Phosphomud (Part Two)
}

\author{
Suzan S. Ibrahim ${ }^{1}$, Khaled E. Yassin ${ }^{1} \&$ Tawfik R. Boulos ${ }^{1}$ \\ ${ }^{1}$ Minerals Beneficiation and Agglomeration Dept., Central Metallurgical Research and Development Institute \\ (CMRDI), Helwan, Cairo, Egypt \\ Correspondence: Suzan S. Ibrahim, Minerals Beneficiation and Agglomeration Dept., Central Metallurgical \\ Research and Development Institute (CMRDI), Helwan 11421 Cairo, Egypt. E-mail: suzansibrahim@gmail.com
}

Received: May 2, 2019

doi:10.5539/enrr.v9n2p102
Accepted: May 20, 2019

Online Published: May 23, 2019

URL: https://doi.org/10.5539/enrr.v9n2p102

\begin{abstract}
Mineral industries in common generate a lot of rejects in the form of fines and slimes, which ultimately create environmental and social problems besides causing losses of mineral values. In view of the recent stringent policy imposed on the environment, there is an urgent need to attempt possible simple and cheap solutions to such problems. These slimes have long been considered in the industry to be unrecoverable. It has been standard practice over many years in the phosphate industry to separate and discard the fines and ultrafine particles.

In this respect, the present study shed light on the recovery of super and ultrafine phosphate of a phosphomud produced after the processing of an East Mediterranean phosphate ore. Falcon Concentrator model SB40-VFD (semi-continuous with variable frequency drive) was used in this study to recover the -32 micron phosphate fines of D50=11 micron. The effect of the main variables of the semi-continuous Falcon concentrator model SB40-VFD, including the bowl rotation frequency $\mathrm{Hz}$, the fluidizing water pressure $\mathrm{psi}$, and feeding rate $\mathrm{g} / \mathrm{min}$ on the separation efficiency were followed up. In addition, two feeding modes based on a particle size-by-size were tried in this study: The sample was fed as a global -32 micron sample or as two fractions, $-32+11$ micron, and -11 micron samples. Central Composite Rotatable Design (CCRD) was applied on the Falcon separation of the -11 micron fraction with $\mathrm{D} 50<3$ micron alone to model and optimize the separation process for the two responses: the recovered phosphate grade and recovery.

Results showed that the phosphate fines containing $14.73 \% \mathrm{P}_{2} \mathrm{O}_{5}, 15.03 \%$ acid insoluble, and $19.07 \%$ loss in ignition was recovered with grade and $\mathrm{P}_{2} \mathrm{O}_{5}$ recovery reaching $28.29 \%$, and $95.97 \%$ in case of separating the overall -32 micron sample as one feed. In case of the fractionated feeding samples, the total grade and recovery reached $29.21 \%$, and $88.42 \%$, respectively. The application of the CCRD results showed that the bowl rotation frequency showed to have the main irreversible effect on the product grade, where the fluidizing water pressure had the main reversible effect on the recovery. On the other hand, feeding rate showed some effect on the product grade with almost no effect on its $\mathrm{P}_{2} \mathrm{O}_{5}$ recovery\%.
\end{abstract}

Keywords: Phosphate Fines Separation, Falcon SB Concentrator, Process Optimization

\section{Introduction}

Mineral industries in common generate a lot of rejects in the form of fines and slimes, which ultimately create environmental and social problems besides causing losses of mineral values. In view of the recent stringent policy imposed on the environment, there is an urgent need to attempt possible simple and cheap solutions to such problems. These slimes have long been considered in the industry to be unrecoverable. It has been standard practice over many years in the phosphate industry to separate and discard the fines and ultrafine particles.

The world population is projected to reach nine billion by 2050 , and in the coming years, global food demand is expected to increase by $50 \%$ or more. Higher crop productivity gains in the future will have to be achieved in developing countries through better natural resources management and crop improvement. After nitrogen, phosphorus (P) has more widespread influence on both natural and agricultural ecosystems than any other essential plant element. It has been estimated that 5.7 billion hectares of land worldwide contain insufficient amounts of available $\mathrm{P}$ for sustainable crop production, and $\mathrm{P}$ deficiency in crop plants is a widespread problem in various parts of the world. However, it has been estimated that worldwide minable P could last less than 40 years. For 
sustaining future food supplies, it is vital to enhance plant P use efficiency (Cordell \& White, 2015, pp. 337-350; Chen \& Graedel, 2016, pp. 139-152; Fageria et al., 2017, p. 360).

Phosphate beneficiation plants currently pump hundreds of thousands of gallons of fine refuse into waste impoundments every minute. This refuse contains not only fine phosphate, considered unrecoverable by current industrial practice, but also coarse phosphate that has been misplaced due to sizing inefficiencies. Unfortunately, this lost phosphate is a large portion of the total valuable mineral extracted during the mining process. Its rejection represents poor separation and energy efficiency, and its recovery would reduce production costs and lessen the amount of waste sent to impoundments (Kohmuench, 2003; Negm \& Abouzeid, 2008, pp. 5-16; Teague \& Lollback, 2012, pp. 52-59; Mew, 2016, pp. 1008-1012; Geissler et al., 2015, pp. 246-258).

Fine particles in mineral ores are the most valuable because they are the most liberated. However, they are also the most expensive and difficult to recover and concentrate. There are many advanced techniques which are being applied for processing of different fines and ultra fines. In this respect, the enhanced gravity separators could be used where their fast rotating bowl generates an artificially enhanced gravity field several hundred times greater than Earth's gravity that can treat the large flow rates of fine and ultrafine particles with high separation efficiency (Bradley et al., 2000).

The Falcon Concentrators are used to perform separations on the basis of density differences between the dispersed particulate phases with the lowest separation density (d50) as a result of its ability to provide the maximum centrifugal field of $300 \mathrm{~g}$ 's. The parameters that affect the performance of the Falcon Concentrator are the gravity force (g's), water pressure (psi), feed rate ( $1 / \mathrm{min})$, and solid concentration (solid\%). The success of concentration with the Falcon Gravity Concentrator depends on the selection of suitable parameter levels (Özgen, 2016). Different mechanisms have been identified as playing significant roles in the separation taking place inside the bowl such as particle differential settling in the bottom region of the bowl or near the film inlet (Laplante \& Shu, 1993; Laplante et al., 1994, 2013; Abela, 1997; Laplante \& Nickoletopoulos, 1997; McAlister \& Armstrong, 1998; Zhao et al., 2006; Deveau, 2006; El-Midany \& Ibrahim, 2011).

Published studies have identified two distinct particle separation mechanisms inside the Falcon concentrator (Laplante et al., 1994; Honaker et al., 1996; Laplante \& Nickoletopoulos, 1997; Abela, 1997): differential particle settling within the thickness of the liquid film that flows on the surface of the rotating bowl, and particle rearrangement inside the granular bed (Majumder et al., 2006) that forms inside the Falcon's retention zone. Weak parallel force component helps in migration of layers in upward direction. In the retention zone the upward movement of the heavier layer is restricted so as to report to overflow. Thus, the heavier particle layer remains at rest. Centrifugal force helps in the control of discharge of heavy materials through a pinch valve fitted on the wall of the bowl in the retention zone (Rath \& Singh, 2007).

Operating conditions (Laplante et al., 1994; Laplante \& Nickoletopoulos, 1997) have derived a separation model for the Falcon concentrator. Through interpretation of their results, the researchers identified and discussed separation mechanisms that most likely take place inside the Falcon; however, the model they derived in the end is utterly empirical and does not embed any physics of the separation. Detailed studies about Falcon bowls that use fluidization and the role of the particle bed on concentrate recovery were done (Honaker et al., 1994; Honaker et al., 1996). The relation between bed composition and the quality of the separation for fine particles was also investigated (Deveau, 2006). They showed that a layer of better quality concentrate builds on the surface of the bed, which agrees with our hypothesis that differential settling plays a key role for ultrafine particle separation. Indeed, should bed rearrangement occur with fine particles, the surface of the bed should contain the lighter and finer particles, those most susceptible to be re-suspended. However, it turns out that the region of the bed with the highest quality, in terms of separation, is in fact the one where the sedimenting particles just enter the bed. It is expected that ultrafine particles having low inertia cannot clear themselves a path towards the inside of the particle bed. This observation confirms the conclusion that particle bed rearrangement is not suitable for the recovery of ultrafine particles with a Falcon concentrator (Luttrell et al., 1995).

Falcon concentrators have three bowl series that differ by the way they trap particles once particles have been classified by differential settling in the flowing film. Falcon SB series uses fluidized annular grooves upstream of the bowl outlet, where the retention capacity of the bowl can thus be set by adjusting the counter-pressure flow rate. Falcon UF series uses smooth bowls with a slight reduction in diameter at the outlet. This lip creates a nonflowing region whose volume varies with the bowl's opening angle. In this case, the film flows over a retention zone that has no fluidization counter-pressure. Both series are essentially semi-batch: "heavy" particles are recovered by interrupting operation and emptying the retention zone before a new operating cycle starts. The third design - C series - operates similarly to the UF series, but adds a slot in the retention zone that is equipped with 
discharge valves with variable size apertures. In this way, the discharge rate in the retention zone can be adjusted, which makes it possible to operate the bowl continuously (Laplante \& Shu, 1993; Laplante et al., 1994; Abela, 1997; Honaker et al., 1996; Laplante \& Nickoletopoulos, 1997; McAlister \& Armstrong, 1998; Holtham et al., 2005; Deveau, 2006; Jean-S'ebastien et al., 2010).

The application of the centrifugal concentration gains importance in the world scenario, considering the low environmental impact and the concentration of fine particles. Falcon concentrators have found a wide number of applications in industry for separating and concentrating objective minerals on the basis of density difference. Tailings from Odisha Mining Corporation Ltd. chromite plant in India and from a Northeastern Brazil chromite concentration plant were successfully treated using Falcon Concentrator (Rath et al., 2017, pp. 644-649; Freire et al., 2019, pp. 147-152). An extraction of copper from recycling plant slag by using falcon concentrator was conducted. The test material was processed as the whole particle distribution. The best results were $4.51 \%$ grade and $15.07 \%$ recoveries with $406 \%$ of enrichment ratio, whereas the narrow particle size distribution has $6.50 \%$ grade and $14.81 \%$ recoveries with $619 \%$ of enrichment as the average of all three particle size distributions (Kademli \& Aydogan, 2019, pp. 117-128).

In minerals processing, slimes accumulation in most of the ore bodies are due to weathering and decomposition of certain rock components. Subsequently further secondary slimes are produced during comminution of an ore to its liberation size. As the quantity of the secondary slime is dependent on the liberation size and the natural breakage characteristics of the ore and to some extent on the comminution process used, attempts are possible to minimize the excess production of fines. However, there is nothing that can be done about the presence of primary slimes.

This article aims at application of such technology for the separation of the superfine and ultrafine phosphate of a phosphomud produced after the processing of an East Mediterranean phosphate ore (Ibrahim et al., 2019), looking forward for a maximum recovery of the process. This might be a better use of slimes instead of sending them to the dump. It is, as a matter of fact, a continuation of Part One which dealt with the +0.071 mm size fraction (Ibrahim et al., 2019).

\section{Method}

The sample under investigation was the -32 micron primary fines after the processing of an East Mediterranean phosphate ore sample from the Red Sea Region, Egypt, (Ibrahim et al., 2019). Complete evaluation of the sample was carried out using the X-ray fluorescence analysis, X-ray diffraction phase analysis, petrography microscope investigation, as well as laser grain size determination.

The Falcon SB40-VFD (semi-continuous with variable frequency drive) concentrator was used in this study to recover the phosphate minerals found in these fines. The concentrator has maximum bowl rotor frequency of $80 \mathrm{~Hz}$ to reach the maximum gravity acceleration of $300 \mathrm{~g}$, Table 1 .

Table 1. Relation between bowl frequency, speed, and gravity acceleration

\begin{tabular}{lll}
\hline Rotation frequency, $\mathrm{Hz}$ & Rotation speed, rpm & Gravity, G \\
\hline 55 & 1604 & 148 \\
60 & 1750 & 176 \\
65 & 1896.26 & 203.57 \\
70 & 2041.29 & 244.99 \\
80 & 2333.04 & 306.71 \\
\hline
\end{tabular}

For separation tests, $50 \mathrm{~g}$ samples were prepared as $25 \%$ slurry solutions. The samples were kept in continuous rapid agitation during the feeding process. After many exploratory tests, it was noticed that no separation occurred below $50-55 \mathrm{~Hz}$ or above $75 \mathrm{~Hz}$ rotation frequency. Accordingly the Falcon separation tests were conducted between $60-75 \mathrm{~Hz}$ rotation frequency, and at different water pressures from 3 to 7 psi. Feeding rate was kept at $8 \mathrm{~g} / \mathrm{min}$ throughout all the tests. Evaluation of different tests was carried out by measuring the grade and $\mathrm{P}_{2} \mathrm{O}_{5}$ recovery $\%$ of different phosphate concentrate products.

Two separation tracks were applied in this study. The first track was separating the overall phosphate fines as one batch feeding material, whereas in the second track, separating the phosphate fines as two fractions: $-32+11$ micron fraction, and -11 micron fraction was carried out, Table 2.

Table 2. Chemical analysis of the classified two fractions samples 


\begin{tabular}{lllll}
\hline Fraction & $\mathrm{Wt} \%$ & $\mathrm{P}_{2} \mathrm{O}_{5} \%$ & I.R.\% & L.O.I.\% \\
\hline$-32+11$ um & 45.00 & 16.88 & 6.88 & 20.31 \\
-11 um & 55.00 & 13.52 & 19.75 & 17.86 \\
Total & 100 & 15.03 & 13.96 & 18.96 \\
Org & & 14.73 & & \\
\hline
\end{tabular}

On the other hand, the separation of the -11 micron fraction using the Falcon Concentrator was re-treated using the central composite rotatable design (CCRD) to model and optimize the separation process, besides following up the mutual interaction effects of Falcon working variables on the separation efficiency. The statistical design was constructed, Table 3 .

Table 3. Central composite rotatable design (CCRD) application for Falcon separation of the -11 micron fraction, variables limits

\begin{tabular}{lllllll}
\hline Factor & Symbol & & \multicolumn{4}{c}{ Coded Variable Level } \\
& & Lowest $-\beta$ & Low -1 & Centre 0 & High +1 & Highest $+\beta$ \\
\hline Rotor frequency, Hz & $\mathrm{A}$ & 55 & 60 & 65 & 70 & 80 \\
Water pressure, psi & $\mathrm{B}$ & 2 & 3 & 5 & 7 & 8 \\
Feeding rate, g/min & $\mathrm{C}$ & 4 & 6 & 8 & 10 & 12 \\
\hline
\end{tabular}

\section{Results and Discussion}

\subsection{Original Sample Characterization}

The laser grain size analyzer showed that the D50 of the fines sample was about 11 micron, Figure 1 . On the other hand, particle size distribution of -11 micron fraction is shown in Figure 2. The fines sample contained $14.73 \%$ $\mathrm{P}_{2} \mathrm{O}_{5}, 10.84 \% \mathrm{SiO}_{2}, 49.79 \% \mathrm{CaO}$, and $19.07 \%$ loss in ignition, Table 4 . The main minerals constituting the sample were hydroxy-apatite, calcite, quartz, and francolite, Figure 3. Hydroxy-apatite $\mathrm{Ca}_{5}\left(\mathrm{PO}_{3}\right)_{3} \mathrm{OH}$ was found as monoclinic crystals with a semi-quantitative amount reaching $27.90 \%$, where calcite was found as rhombohydral crystals with a semi quantitative amount reaching 36.50\%. Quartz was found as hexagonal crystals with semiquantitative amount reaching 6.80\%, Figure 3. On the other hand, francolite $(\mathrm{Ca}, \mathrm{Mg}, \mathrm{Sr}, \mathrm{Na})_{10}\left(\mathrm{PO}_{4}, \mathrm{SO}_{4}, \mathrm{CO}_{3}\right)_{6} \mathrm{~F}_{2-3}$ was present as hexagonal crystals with a semi-quantitative amount reaching $24.2 \%$, Figure 3 .

The petrography examination of different polished and thin sections of the sample showed that it could actually be defined as the "phosphomud" and it could be called the microsphorite and orthochemical phosphate. They are formed mainly from two major constituents, the matrix which was the original groundmass of the rock (phosphatic matrix) and the cementing material (silica and carbonate materials) that are presented as the intra-granular binding material between phosphate grains, Figure 4, and as the inter-granular cavity fills, Figure 4 . The phosphomud was the primary in-situ phosphate precipitation, which was kept from modification into other forms by the quiet environment of formation, consolidation and burial. All types of phosphomud are composed of isotropic cryptocrystalline carbonate fluorapatite (francolite), in addition to various amounts of organic material and minute inclusions of non-phosphatic materials (Al-Bassam et al., 2010).

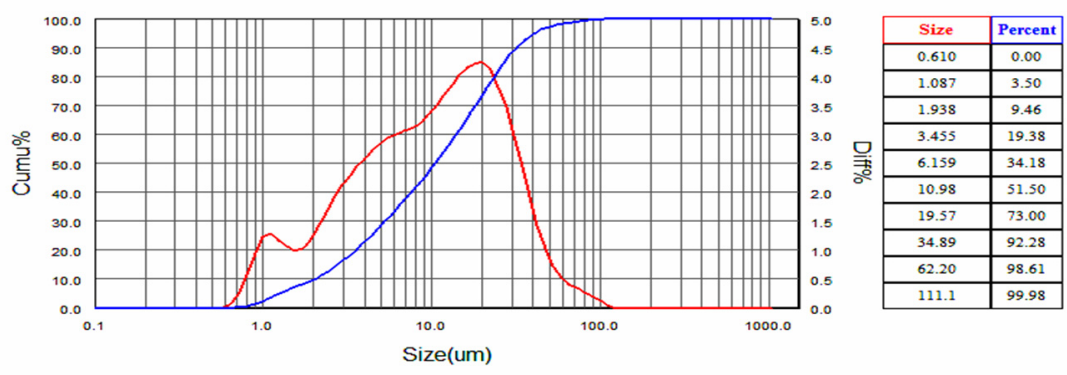

Figure 1. Particle size analysis of the sample under investigation 


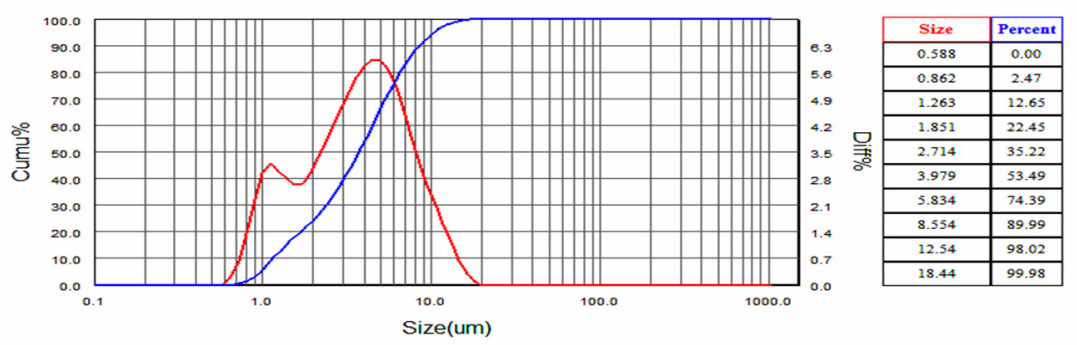

Figure 2. Particle size distribution of -11 micron fraction

Table 4. Chemical analysis of the original phosphate fines sample

\begin{tabular}{llll}
\hline Constituent & $\%$ & Constituent & $\%$ \\
\hline $\mathrm{P}_{2} \mathrm{O}_{5}$ & 14.73 & $\mathrm{TiO}_{3}$ & 0.14 \\
$\mathrm{SiO}_{2}$ & 10.84 & $\mathrm{Cr}_{2} \mathrm{O}_{3}$ & 0.0434 \\
$\mathrm{CaO}$ & 49.79 & $\mathrm{MnO}$ & 0.0262 \\
L.O.I. & 19.07 & $\mathrm{SrO}$ & 0.141 \\
$\mathrm{Al}_{2} \mathrm{O}_{3}$ & 1.04 & $\mathrm{ZnO}$ & 0.061 \\
$\mathrm{Fe}_{2} \mathrm{O}_{3}$ & 1.55 & $\mathrm{NiO}$ & 0.0107 \\
$\mathrm{MgO}$ & 0.63 & $\mathrm{Y}_{2} \mathrm{O}_{3}$ & 0.0116 \\
$\mathrm{Na}_{2} \mathrm{O}$ & $\mathrm{CuO}$ & 0.0114 \\
$\mathrm{SO}_{3}$ & 0.38 & $\mathrm{BaO} 2$ & 0.0253 \\
$\mathrm{~F}$ & 0.69 & $\mathrm{Cl}$ & 0.241 \\
\hline
\end{tabular}

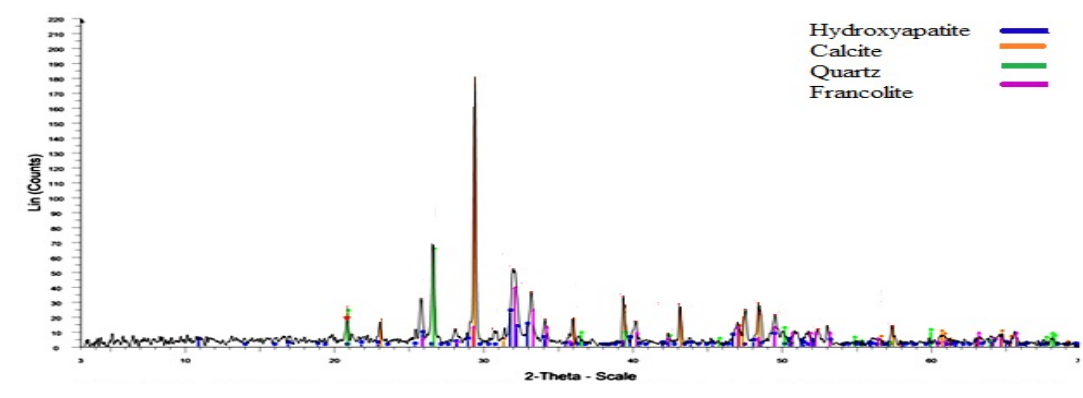

Figure 3. XRD analysis of the sample under investigation
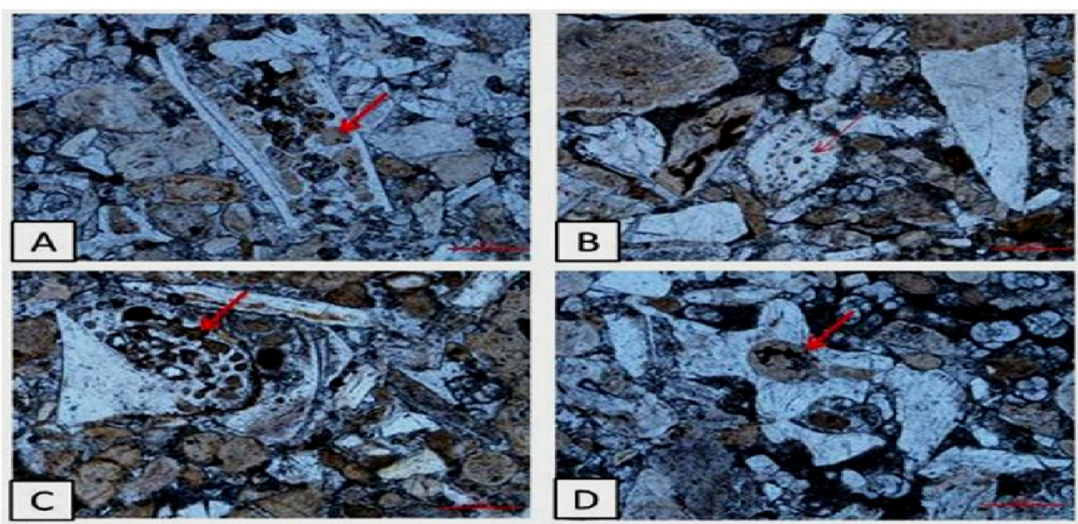

Figure 4. Petrography photos (PPL) showing the micronized phosphate: (A) filling cavities within fish skeleton, (B) and (C) as phosphate-mud filling pores within fish teeth, (D) filling the cavity of vertebra 


\subsection{Recovery of Phosphate Fines Using Falcon Concentrator}

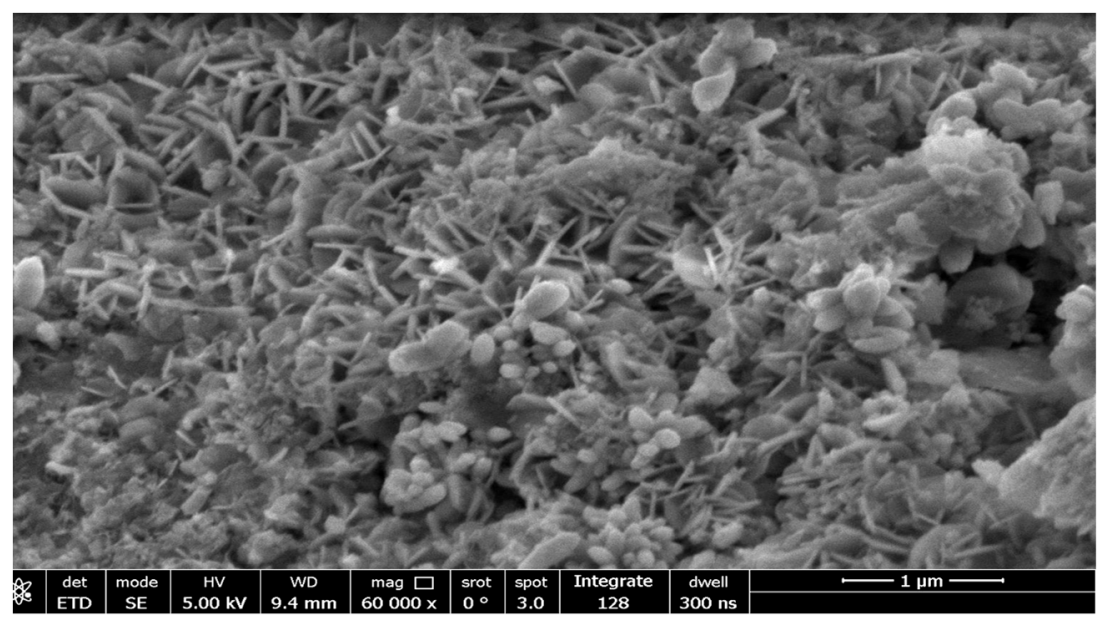

Figure 5. SEM picture of concentrate product

Table 5. Falcon Concentrator separation tests of -32 micron sample at rotation frequency $70 \mathrm{~Hz}$

\begin{tabular}{|c|c|c|c|c|c|c|c|c|}
\hline Product & Pressure, psi & Opt. Wto & & $\mathrm{P}_{2} \mathrm{O}_{5} \%$ & $\mathrm{P}_{2} \mathrm{O}_{5}$ Rec. $\%$ & & I.R.\% & LOI\% \\
\hline $\mathrm{H} 1$ & 3 & 27.82 & & 25.17 & 47.54 & & 6.36 & 17.76 \\
\hline $\mathrm{L} 1$ & 3 & 72.18 & & 15.01 & & & 14.04 & 17.64 \\
\hline $\mathrm{H} 2$ & 4 & 25.59 & & 26.18 & 45.48 & & 6.36 & 18.81 \\
\hline L2 & 4 & 74.41 & & 13.77 & & & 12.50 & 17.43 \\
\hline H3 & 5 & 18.38 & & 26.49 & 33.05 & & 5.28 & 18.08 \\
\hline L3 & 5 & 81.62 & & 15.12 & & & 12.10 & 18.21 \\
\hline H4 & 6 & 15.32 & & 27.39 & 28.49 & & 4.32 & 18.54 \\
\hline L4 & 6 & 84.68 & & 15.25 & & & 12.36 & 18.16 \\
\hline H5 & 7 & 4.45 & & 30.62 & 9.25 & & 2.03 & 18.11 \\
\hline L5 & 7 & 95.55 & & 16.36 & & & 12.56 & 18.07 \\
\hline \multicolumn{9}{|c|}{ Scavenging tests of L5 } \\
\hline Product & Frequency & Pressure & \multicolumn{2}{|c|}{ Operational Wt., \% } & \multicolumn{2}{|r|}{$\mathrm{P}_{2} \mathrm{O}_{5} \%$} & \multicolumn{2}{|r|}{$\mathrm{P}_{2} \mathrm{O}_{5}$ Rec. Wt., \% } \\
\hline $\mathrm{H} 6$ & 70 & 7 & \multicolumn{2}{|l|}{15.16} & \multicolumn{2}{|r|}{27.86} & \multicolumn{2}{|r|}{28.67} \\
\hline H7 & 65 & 7 & \multicolumn{2}{|l|}{10.13} & \multicolumn{2}{|r|}{29.15} & \multicolumn{2}{|r|}{20.05} \\
\hline H8 & 65 & 4 & \multicolumn{2}{|l|}{20.22} & \multicolumn{2}{|r|}{27.68} & \multicolumn{2}{|r|}{38.00} \\
\hline Total H & & & \multicolumn{2}{|l|}{49.96} & \multicolumn{2}{|r|}{28.29} & \multicolumn{2}{|r|}{95.97} \\
\hline Final L & & & \multicolumn{2}{|l|}{50.04} & \multicolumn{2}{|r|}{1.19} & \multicolumn{2}{|r|}{4.03} \\
\hline Total & & & \multicolumn{2}{|l|}{100.00} & & 14.73 & \multicolumn{2}{|r|}{100.00} \\
\hline Org. & & & & & & 14.73 & & 100 \\
\hline
\end{tabular}

As light minerals are acquired from the overflowing part; the more the centrifugal power is, the more large and heavy particle will stick to the addition wall of the Falcon Concentrator. At the maximum wash water, the cleanest heavy concentrate will be captured. Accordingly, maximum phosphate grade of $30.62 \% \mathrm{P}_{2} \mathrm{O}_{5}(\mathrm{H} 5)$ with a recovery reaching $9.25 \%$ was obtained at maximum rotation frequency of $70 \mathrm{~Hz}$, and at maximum wash water of $7 \mathrm{psi}$, Table 5. In addition, by re-treating the tail product (L5) at rotation frequency of $70 \mathrm{~Hz}$, followed by another scavenging step at frequency of $65 \mathrm{~Hz}$, and wash water pressure of $7 \mathrm{psi}$, followed by another step at $4 \mathrm{psi}$ with the same rotation frequency of 65 , different phosphate concentrates with $27.86 \%, 29.15 \%$, and $27.68 \% \mathrm{P}_{2} \mathrm{O}_{5}(\mathrm{H} 6, \mathrm{H} 7$, and $\mathrm{H} 8$, 
respectively) were separated with $28.67 \%, 20.05 \%$, and $38.00 \% \mathrm{P}_{2} \mathrm{O}_{5}$ recovery, respectively, Table 5 . It was noticed that the separation of phosphate products $\mathrm{H} 5, \mathrm{H} 6, \mathrm{H} 7$, and $\mathrm{H} 8$ in Table 4 were greatly affected with the gradual decrease in the bowl rotation frequency from $70 \mathrm{~Hz}$ to $65 \mathrm{~Hz}$ and at the same time with the decrease in the wash water pressure from $7 \mathrm{psi}$ to $4 \mathrm{psi}$. This may be explained by the presence of two phosphate minerals (hydroxyapatite and francolite) with different crystal shape and particle sizes, as confirmed by the X-ray diffraction phase analysis of the original sample, Figure 3. In addition, it was noted that the upgrading of phosphate minerals was at the expense of the quartz silica component, while no change in the calcite content was noticed. The overall final phosphate product after the Falcon separation of the fines sample (-32 micron) assayed $28.29 \% \mathrm{P}_{2} \mathrm{O}_{5}$ with a recovery reaching $95.97 \%$, Table 5 . On the other hand, it is suggested that the phosphate concentrate products $\mathrm{H} 5$ and $\mathrm{H} 6$ may be referred to as francolite mineral (they represented about $37.86 \% \mathrm{P}_{2} \mathrm{O}_{5}$ distribution of the whole feeding sample), whereas the phosphate concentrates $\mathrm{H} 7$ and $\mathrm{H} 8$ may be referred to as hydroxyapatite mineral (they represented about $58.05 \% \mathrm{P}_{2} \mathrm{O}_{5}$ distribution of the whole feeding sample). The phase analysis of the original sample showed that the hydroxyapatite content was more than the francolite content, Figure 5.

\subsection{Falcon Separation of Fractionated Phosphate Fines}

The Falcon separation of the size fraction $-32+11$ micron was done at bowl rotation frequency of $70 \mathrm{~Hz}$ and at different wash water pressures, Table 6 . The maximum phosphate grade was $31.43 \% \mathrm{P}_{2} \mathrm{O}_{5}$ with recovery reaching $18.19 \%$ at frequency of $70 \mathrm{~Hz}$ and water pressure of $7 \mathrm{psi}$, Table 6 . It was noticed that separation of different phosphate products occurred at higher bowl rotation frequencies between $70-65 \mathrm{~Hz}$, while wash water pressure controlled their grade and recovery, Table 6 . The wash water pressure acted as a shower facing the heavy products particles. At relatively lower pressure values, large light grains can pass the small heavy grains and escape to the heavy products, yielding a low grade phosphate concentrate with a high weight $\%$, i.e. high recovery $\%$ (H1 and $\mathrm{H} 2$ ), Table 6 . At higher wash water pressures, the water shower was strong enough to remove all light grains and even small heavy particles from its path to yield a maximum phosphate grade reaching $31.43 \% \mathrm{P}_{2} \mathrm{O}_{5}$ with low recovery reaching $18.19 \%$ (H5), Table 6 . By scavenging the tail L5, different high grade phosphate cuts could be produced according to their grain shape and size in sequence by controlling mainly the wash water pressure (H6 and H7), and finally by decreasing both the rotation frequency and water pressure to $65 \mathrm{~Hz}$ and $3 \mathrm{psi}$, respectively, to catch the very fine heavy particles (H8), Table 6. The final phosphate concentrate product after the Falcon separation of the fraction $-32+11$ micron assayed $28.97 \% \mathrm{P}_{2} \mathrm{O}_{5}$ with a recovery reaching $87.81 \%$, Table 6 .

Table 6. Falcon Concentrator separation circuit of $-32+11$ micron fraction

\begin{tabular}{|c|c|c|c|c|c|c|c|}
\hline Product & Frequency & Pressure & Opt. Wt $\%$ & $\mathrm{P}_{2} \mathrm{O}_{5} \%$ & $\mathrm{P}_{2} \mathrm{O}_{5}$ Rec. $\%$ & I.R. $\%$ & $\mathrm{LOI} \%$ \\
\hline H1 & 70 & 3 & 50.75 & 24.66 & 74.14 & 4.88 & 18.36 \\
\hline L1 & & & 49.25 & 7.66 & & 8.55 & 19.22 \\
\hline $\mathrm{H} 2$ & 70 & 4 & 43.46 & 25.44 & 65.50 & 3.33 & 18.88 \\
\hline $\mathrm{L} 2$ & & & 56.54 & 10.28 & & 9.11 & 20.52 \\
\hline $\mathrm{H} 3$ & 70 & 5 & 30.55 & 27.11 & 49.06 & 3.10 & 17.57 \\
\hline L3 & & & 69.45 & 10.72 & & 7.87 & 18.46 \\
\hline $\mathrm{H} 4$ & 70 & 6 & 15.36 & 29.10 & 26.48 & 2.55 & 18.00 \\
\hline L4 & & & 84.64 & 13.22 & & 7.21 & 18.62 \\
\hline H5 & 70 & 7 & 9.77 & 31.43 & 18.19 & 2.10 & 17.12 \\
\hline L5 & & & 90.23 & 13.66 & & 7.13 & 18.36 \\
\hline \multicolumn{8}{|c|}{ Scavenging tests of L5 } \\
\hline Product & Frequency & Pressure & Operational Wt., $\%$ & $\mathrm{P}_{2} \mathrm{O}_{5} \%$ & $\mathrm{P}_{2} \mathrm{O}_{5}$ Rec. Wt., \% & & \\
\hline H6 & 70 & 7 & 20.52 & 27.66 & 33.62 & & \\
\hline H7 & 70 & 4 & 5.65 & 30.08 & 10.07 & & \\
\hline H8 & 65 & 3 & 15.23 & 28.74 & 25.93 & & \\
\hline Total H & & & 51.17 & 28.97 & 87.81 & & \\
\hline Final L & & & 48.83 & 4.21 & 12.19 & & \\
\hline
\end{tabular}

On the other hand, the Falcon separation of the fraction - 11 micron was completely done at bowl rotation frequency of $70 \mathrm{~Hz}$ and at different wash water pressures, Table 7 . The maximum phosphate grade was $32.44 \% \mathrm{P}_{2} \mathrm{O}_{5}$ with recovery reaching $13.82 \%$ at frequency of $70 \mathrm{~Hz}$ and water pressure of $6 \mathrm{psi}$, Table 7. It was noticed that separation of different phosphate products usually happens at higher bowl rotation frequency of $70 \mathrm{~Hz}$, whereas wash water pressure controlled their grade and recovery, Table 7. By scavenging the tail L4, different high grade phosphate 
cuts could be produced according to their grain shape and size in sequence by decreasing both the rotation frequency from $70 \mathrm{~Hz}$ to $65 \mathrm{~Hz}$, and the wash water pressure from 5 to 3 to 2 psi to catch the very fine heavy particles from a feed sample of D50< 4 micron, Figure 7. The final phosphate concentrate product after the Falcon separation of the fraction -11 micron assayed $29.49 \% \mathrm{P}_{2} \mathrm{O}_{5}$ with a recovery reaching $88.42 \%$, Table 7 .

Table 7. Falcon separation tests of the -11um fraction

\begin{tabular}{|c|c|c|c|c|c|c|c|}
\hline Product & Frequency & Pressure & $\mathrm{Wt} \%$ & $\mathrm{P}_{2} \mathrm{O}_{5} \%$ & $\mathrm{P}_{2} \mathrm{O}_{5} \% \mathrm{Rec}$ & I.R.\% & $\mathrm{LOI} \%$ \\
\hline $\mathrm{H} 2$ & 70 & 3 & 24.45 & 26.44 & 47.82 & 4.28 & 18.00 \\
\hline L2 & & & 75.55 & 8.62 & & 24.75 & 17.81 \\
\hline H3 & 70 & 4 & 16.37 & 28.66 & 34.70 & 3.63 & 17.55 \\
\hline L3 & & & 83.63 & 9.00 & & 21.90 & 16.92 \\
\hline $\mathrm{H} 4$ & 70 & 5 & 10.23 & 30.88 & 23.37 & 2.50 & 18.74 \\
\hline L4 & & & 89.77 & 11.09 & & 20.72 & 17.75 \\
\hline H5 & 70 & 6 & 5.76 & 32.44 & 13.82 & 15.29 & 2.11 \\
\hline L5 & & & 94.24 & 9.98 & & & 19.83 \\
\hline H6 & 70 & 7 & 0.00 & & & & \\
\hline L6 & & & 100.00 & & & & \\
\hline \multicolumn{8}{|c|}{ Scavenging Separation of L4 } \\
\hline $\mathrm{H} 7$ & 70 & 5 & 5.55 & 29.88 & 13.57 & 3.01 & 17.69 \\
\hline $\mathrm{H} 8$ & 65 & 3 & 15.44 & 28.59 & 36.12 & & \\
\hline H9 & 65 & 2 & 5.42 & 29.04 & 12.88 & & \\
\hline Total heavy & & & 36.64 & 29.49 & 88.42 & & \\
\hline L9 & & & 63.34 & 4.55 & & 23.47 & 17.63 \\
\hline
\end{tabular}

Results in Tables 6 and 7 showed that the Falcon SB 40 recovered the fractionated phosphate fines $-32+11$ micron and -11 micron as an overall concentrate assaying $29.21 \% \mathrm{P}_{2} \mathrm{O}_{5}$ with a recovery reaching $85.63 \%$ in a product weighing 43.18\%, Tables 6 and 7. Accordingly, it could be concluded that the Falcon separation of the global phosphate fines -32 micron feed was better than by fractionation as two feeds $-32+11$ micron and -11 micron with respect to recovery $(95.97 \%$ and $88.42 \%$, respectively), but the one global feeding mode was preferable referring to the product grade $(28.29 \%$ and $29.21 \%$, respectively), Tables 5, 6, and 7 .

\subsection{Central Composite Rotatable Design (CCRD) Application of the-11 Micron Fraction}

Results of the CCRD application for Falcon separation of the -11 micron fraction is shown in Table 8 . However, the graphs shown in Figure 6 illustrate the effect of bowl rotation frequency, wash water pressure, and feeding rate on the Falcon separation efficiency with respect to the product grade $\left(\mathrm{P}_{2} \mathrm{O}_{5} \%\right)$ and recovery responses, whereas Figure 7 illustrates their normal plot residuals. Results show that with increasing rotation frequency, the product grade values increase at the same water pressure (runs 1,2, and 12), Table 8. As the slurry travels up the wall, the relatively larger particles stratify next to the wall of the bowl and the small particles move outwards towards the centre of the bowl. The heavy particles (phosphate) were collected in the concentrate basket where water washes out light particles (mainly silica) into the tailings stream. Therefore when rotation frequency (gravity force) increases, centrifugal power increases and heavy particles stick to the wall of the bowl better. By increasing the centrifugal force, a cleaner concentrate was obtained. However, as the water pressure decreases, the recovery response values showed obvious increasing at the expense of the grade which showed remarkable decrease by decreasing the wash water pressure (runs 1,3, and 6), Table 8. Wash water was used for carrying the light particles; however, in higher water pressures, heavy particles start to be carried out with light particles. Because of this, when the water pressure was increased, as light particles were carried as well, the quality of the produced phosphate was increased. On the other hand, when the feeding rate increases, a decrease in the residence time inside the Falcon occurs, this causing a decrease in the phosphate product quality.

The regression equations in terms of coded factors are:

$$
\begin{aligned}
& \mathrm{P}_{2} \mathrm{O}_{5} \%=+26.12+10.01 * \mathrm{~A}+4.47 * \mathrm{~B}+4.63 * \mathrm{C}+5.22 * \mathrm{~A}^{2}-1.32 * \mathrm{~B}^{2}-7.08 * \mathrm{C}^{2}+9.35 * \mathrm{~A} * \mathrm{~B}+1.74 * \mathrm{~A} * \mathrm{C}+11.18 \\
& * \mathrm{~B} * \mathrm{C} \\
& +2.09 * \mathrm{~A} * \mathrm{~B}+2.15 * \mathrm{~A} * \mathrm{C}-10.72 * \mathrm{~B} * \mathrm{C}
\end{aligned}
$$


From equation 1, it is shown that rotation frequency, water pressure, and feeding rate have irreversible effect on the product grade $\left(\mathrm{P}_{2} \mathrm{O}_{5} \%\right)$. By increasing the value of these parameters, the grade of the phosphate product increases. Results show that the rotation frequency has the dominant effect whereas the water pressure and feeding rate have lesser effect with equal amount. This could be explained whereas the high rotation frequencies yield greater gravitational force which can create magnification to the density difference between phosphate and silica that may overcome the high finance of both minerals in the feeding sample. By increasing the rotation frequency from 65 to $70 \mathrm{~Hz}$, the grade of the phosphate product increases from $22.88 \%$ to $26.01 \%$ at the same water pressure of $4 \mathrm{psi}$ and feeding rate of $8 \mathrm{~g} / \mathrm{min}$. Contrary to response A, the rotation frequency and water pressure have reversible action on response $\mathrm{B}\left(\mathrm{P}_{2} \mathrm{O}_{5}\right.$ Rec. \%) with water pressure predominating effect, whereas the feeding rate has no effect, equation 2. At rotation frequency and water pressure reaching $70 \mathrm{~Hz}$ and $4 \mathrm{psi}$, respectively, the $\mathrm{P}_{2} \mathrm{O}_{5} \%$ recovery reached $33.03 \%$; by decreasing the speed to $65 \mathrm{~Hz}$ (at the same water pressure of $4 \mathrm{psi}$ ), the recovery increased to $37.70 \%$.

By increasing the water pressure to $6 \mathrm{psi}$ (at the same rotation frequency of $70 \mathrm{~Hz}$ ), the recovery sharply decreased to $12.98 \%$, Table 8 . At the same rotation frequency of $70 \mathrm{~Hz}$ and water pressure of $4 \mathrm{psi}$, the $\mathrm{P}_{2} \mathrm{O}_{5} \%$ recovery reached $48.20 \%$ at feeding rate of $10 \mathrm{~g} / \mathrm{min}$. By decreasing the feeding rate to $6 \mathrm{~g} / \mathrm{min}$, the $\mathrm{P}_{2} \mathrm{O}_{5} \%$ recovery showed no change, whereas it reached $48.35 \mathrm{~g} / \mathrm{min}$, Table 8 . By increasing the feeding rate to $8 \mathrm{~g} / \mathrm{min}$., a decrease in the recovery reached $33.03 \mathrm{~g} / \mathrm{min}$., Table 8 . At rotation frequency of $70 \mathrm{~Hz}$ in tests nos. 1,3 , and 6 , by increasing water pressure from 2, 4, and to $6 \mathrm{psi}$, the grade of the phosphate products increases from $19.88,26.01$, to $29.78 \% \mathrm{P}_{2} \mathrm{O}_{5}$ with recovery reaching $62.99,33.03$, and $12.98 \%$, respectively, Table 8 . On the other hand, as the feeding rate increases, the residence time of minerals in the Falcon decreases and the separation of the very fine particles could not be done. For this reason, while maximum recovery of phosphate product was achieved in minimum feed rate; maximum product grade was achieved at moderate feed rate, Table 8 . In case of response A $\left(\mathrm{P}_{2} \mathrm{O}_{5} \%\right)$, the Model F-value of 211.47 implies that the model is significant, as there is only a $0.01 \%$ chance that a "Model F-Value" this large could occur due to noise. In this case $\mathrm{A}, \mathrm{B}, \mathrm{C}, \mathrm{A}^{2}, \mathrm{~B}^{2}, \mathrm{C}^{2}, \mathrm{AB}, \mathrm{AC}$, and $\mathrm{BC}$ are significant model terms. In case of response $\mathrm{B}\left(\mathrm{P}_{2} \mathrm{O}_{5}\right.$ Rec. Wt., \%), the Model F-value of 177.39 implies that the model is significant, as there is only a $0.01 \%$ chance that a "Model F-Value" this large could occur due to noise. In this case A, B, $\mathrm{A}^{2}, \mathrm{~B}^{2}$, $\mathrm{C}^{2}$, and $\mathrm{BC}$ are significant model terms. Results showed that bowl rotation frequency represented the dominated effect on product grade regardless of the sizes. The order of importance of the variables can be shown as rotation frequency $(\mathrm{Hz})>$ washing water pressure $(\mathrm{psi})>$ feeding rate $(\mathrm{g} / \mathrm{min})$. It also shows that as the particle size decreased the rotation frequency requirement increased. When the particle size becomes very fine, the efficiency of gravity separation becomes very poor. Therefore, centrifugal forces and fluidization have been introduced to overcome this limitation.

Table 8. Results of the CCRD application for Falcon separation of the -11 micron fraction

\begin{tabular}{llllllll}
\hline \multirow{2}{*}{ Std } & Run & Block & $\begin{array}{l}\text { Factor 1 } \\
\text { A: Rotation Speed, Hz }\end{array}$ & $\begin{array}{l}\text { Factor 2 } \\
\text { B: Water Pressure, psi }\end{array}$ & $\begin{array}{l}\text { Factor 3 } \\
\text { C: Feeding Rate, g/min }\end{array}$ & $\begin{array}{l}\text { Response 1 } \\
\mathrm{P}_{2} \mathrm{O}_{5} \%\end{array}$ & $\begin{array}{l}\text { Response 2 } \\
\mathrm{P}_{2} \mathrm{O}_{5} \text { Rec., } \%\end{array}$ \\
\hline 12 & 1 & Block 1 & 70.00 & 4.00 & 8.00 & 26.01 & 33.03 \\
5 & 2 & Block 1 & 65.00 & 4.00 & 8.00 & 22.88 & 37.70 \\
7 & 3 & Block 1 & 70.00 & 2.00 & 8.00 & 19.88 & 62.99 \\
4 & 4 & Block 1 & 60.00 & 2.00 & 6.00 & 26.47 & 77.24 \\
10 & 5 & Block 1 & 70.00 & 4.00 & 8.00 & 26.01 & 33.03 \\
8 & 6 & Block 1 & 70.00 & 6.00 & 8.00 & 29.78 & 12.98 \\
13 & 7 & Block 1 & 70.00 & 4.00 & 8.00 & 26.01 & 33.03 \\
6 & 8 & Block 1 & 65.00 & 4.00 & 8.00 & 22.88 & 37.70 \\
1 & 9 & Block 1 & 80.00 & 6.00 & 6.00 & 29.19 & 5.83 \\
11 & 10 & Block 1 & 70.00 & 4.00 & 8.00 & 26.01 & 33.03 \\
2 & 11 & Block 1 & 80.00 & 4.00 & 10.00 & 14.55 & 53.05 \\
9 & 12 & Block 1 & 55.00 & 6.00 & 13.00 & 55.12 \\
3 & 13 & Block 1 & 60.00 & 4.00 & 8.00 & 22.13 & 20.89 \\
14 & 14 & Block 1 & 70.00 & 4.00 & 8.00 & 26.01 & 33.03 \\
16 & 15 & Block 1 & 70.00 & 3.00 & 6.00 & 26.01 & 33.03 \\
15 & 16 & Block 1 & 65.00 & & 16.58 & 62.18 \\
\hline
\end{tabular}




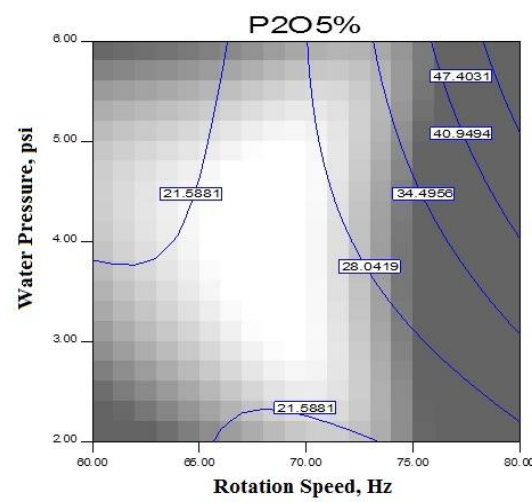

A

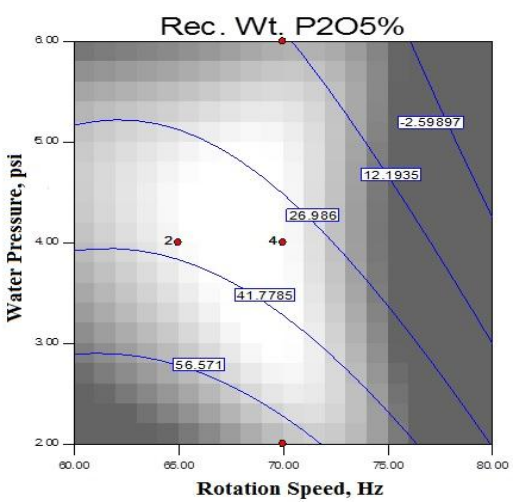

B

Figure 6. Variables effect on concentrate product grade and recovery
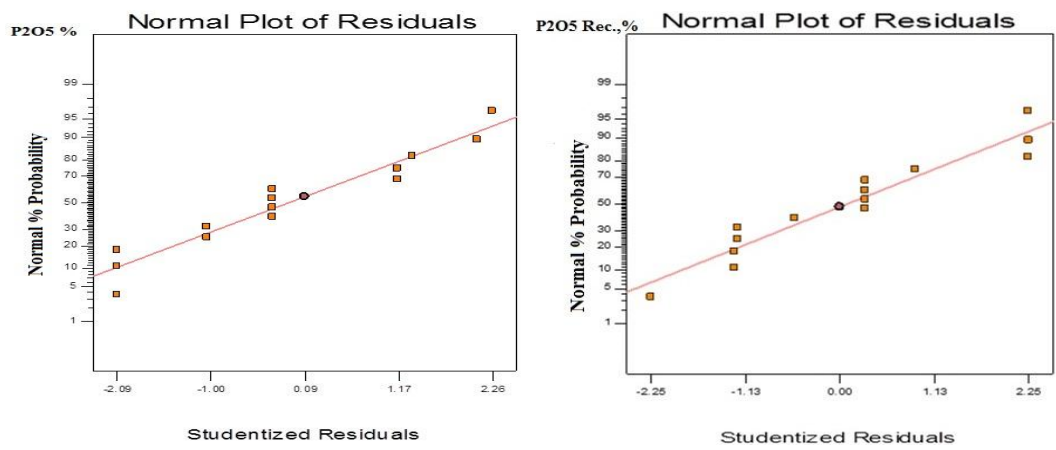

Figure 7. Normal plot of residuals

\subsubsection{Variables Interactions Effects}

At lowest wash water pressure of $2 \mathrm{psi}$, the increase in the rotation frequency showed no effect on the product grade (at feeding rate of 6-7g/min.), while at highest water pressure of $6 \mathrm{psi}$, the increase in the rotation frequency showed notable sharp increase in the product grade; yet, in both cases of water pressure levels, the increase in the rotation frequency shows a great reversible effect on the recovery, Figure 8, A and B. This means that to get a superior product grade, high levels of rotation frequency and wash water pressure are required; yet to get a reasonable recovery value, calculated computational decrease in both parameter levels have to occur (at feeding rate of 6$7 \mathrm{~g} / \mathrm{min}$.).

At low levels of wash water pressure (3-4psi), the increase in the bowl rotation frequency led to remarkable increase in the heavy product grade but equally inversely on its recovery, Figure $8, \mathrm{C}$ and $\mathrm{D}$. At low water pressure levels and at all rotation frequency values, there was no notable effect for the feeding rate between $6-10 \mathrm{~g} / \mathrm{min}$. At high rotation frequency level $(70 \mathrm{~Hz})$, the change in the feeding rate showed remarkable effect on product grade, while it showed much lesser effect on the product recovery throughout all wash water pressure levels, Figure 8, E and F. At high rotation frequency level $(70 \mathrm{~Hz})$ and relatively high feeding rate of $10.00 \mathrm{~g} / \mathrm{min}$, the increase in the wash water pressure caused notable increase in the product grade (Ancia et al., 1997). Yet, at relatively low feeding rate of $6.00 \mathrm{~g} / \mathrm{min}$, the increase in wash water pressure caused pronounced decrease in product grade in case of high rotation frequency of $70 \mathrm{~Hz}$, Figure 8 , E.

The cube graph that illustrates the effect of the studied variables on the $\mathrm{P}_{2} \mathrm{O}_{5} \%$, and $\mathrm{P}_{2} \mathrm{O}_{5}$ Rec. \% of the phosphate concentrate (standard deviation $=0.46,1.84$ and R-squared $=0.99$, respectively) is shown in Figure 9; whereas, Figure 10 shows the variables' conditions for optimum grade and recovery at feeding rate of $6.47 \mathrm{~g} / \mathrm{min}$. It could be concluded that for the -11 micron size fraction, the solid feed rate behaves with relatively positive effect for product grade, whereas it has no effect on the recovery. High rotation frequency and water pressure are required for maximum responses. Generally, when the feed is fine, a higher rotation frequency was needed to achieve maximum recovery. 


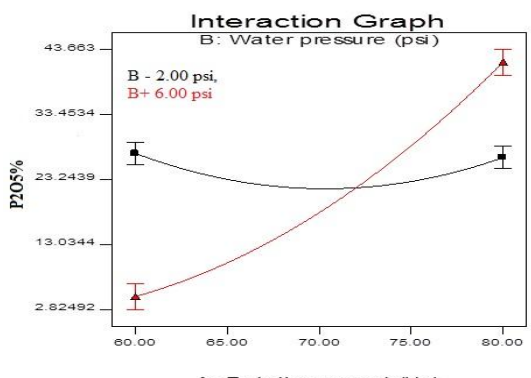

A: Rotation speed (HZ)

A

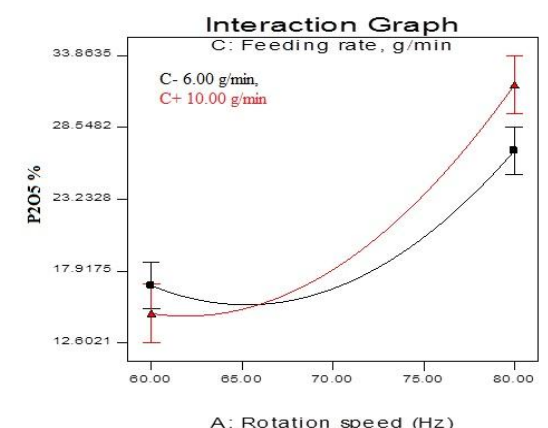

C

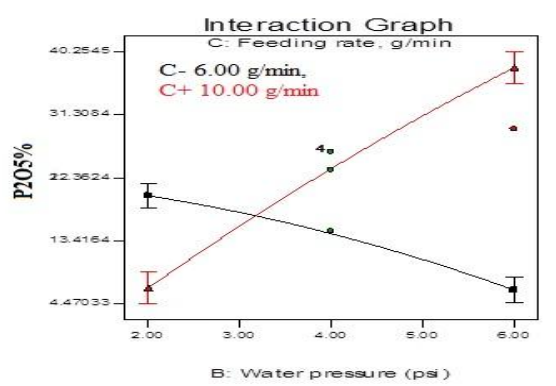

E

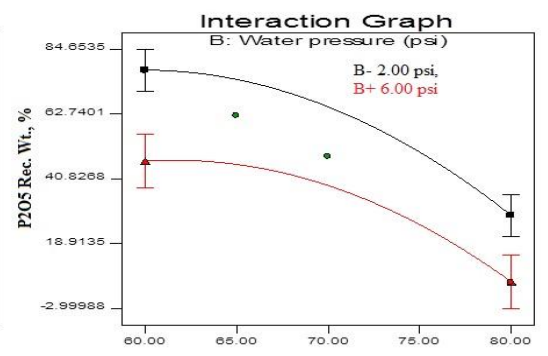

A: Rotation speed $(\mathrm{Hz})$

B

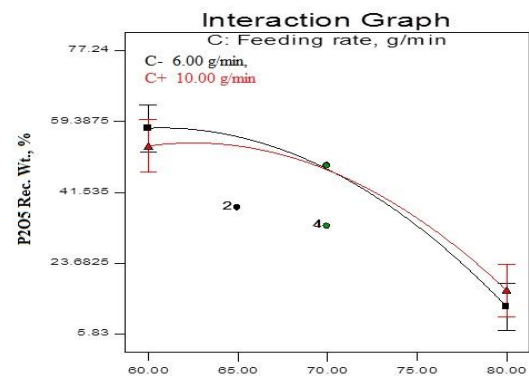

A: Rotation speed (Hz)

$\mathrm{D}$

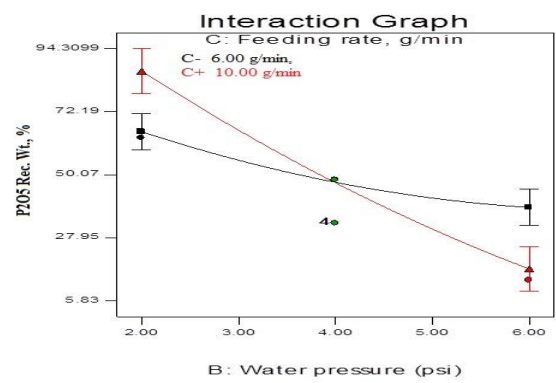

$\mathrm{F}$

Figure 8. Variables interactions effects
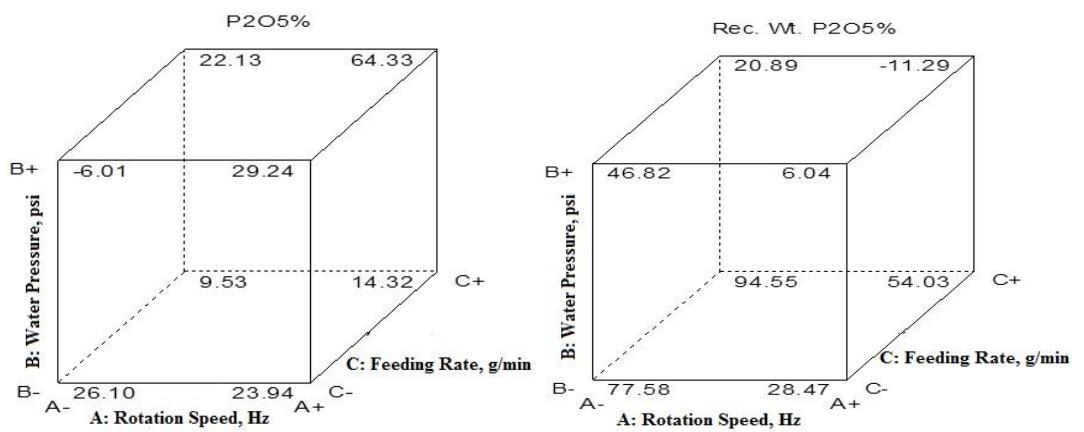

Figure 9. Cube graph showing the effect of the studied variables on the $\mathrm{P}_{2} \mathrm{O}_{5} \%$, and $\mathrm{P}_{2} \mathrm{O}_{5}$ Rec. \%

To globalize the recovery results of the $-0.071 \mathrm{~mm}$ phosphomud component that was produced after the processing of the East Mediterranean phosphate ore sample (Ibrahim et al., 2019), it could be concluded that a final concentrate weighing $60.91 \%$, and assaying $28.48 \% \mathrm{P}_{2} \mathrm{O}_{5}$ with a recovery reaching $89.16 \%$ was produced, Tables 9,10 , and 11 . 

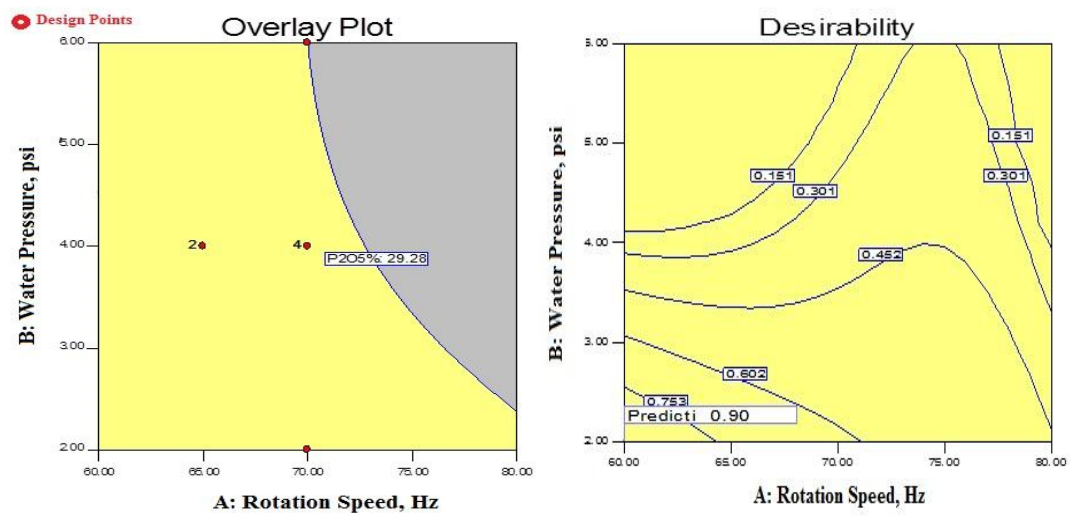

Figure 10. Variables conditions for optimum grade and recovery (at feeding rate of $6.47 \mathrm{~g} / \mathrm{min}$.)

Table 9. Processing results of the attrition scrubbing/classification scheme (Ibrahim et al., 2019)

\begin{tabular}{llll}
\hline Product & Wt., $\%$ & $\mathrm{P}_{2} \mathrm{O}_{5} \%$ & $\mathrm{P}_{2} \mathrm{O}_{5}$ Dist., \% \\
\hline Coarse tail $(+2.30 \mathrm{~mm})$ & 10.72 & 12.24 & 6.74 \\
Attrition concentrate $(-2.30+0.071 \mathrm{~mm})$ & 35.06 & 28.72 & 51.75 \\
Fines $(-0.071 \mathrm{~mm})$ & 43.03 & 18.77 & 41.51 \\
Total & 88.81 & 21.91 & 100.00 \\
\hline
\end{tabular}

Table 10. Processing results of the phosphate fines $(-0.071 \mathrm{~mm})$ after the Falcon treatment

\begin{tabular}{llll}
\hline Product & Wt., $\%$ & $\mathrm{P}_{2} \mathrm{O}_{5} \%$ & $\mathrm{P}_{2} \mathrm{O}_{5}$ Dist., $\%$ \\
\hline$-0.071+0.032 \mathrm{~mm}$ & 8.69 & 27.91 & 10.66 \\
$-0.032 \mathrm{~mm}$ (Falcon Conc.) & 17.16 & 28.29 & 26.75 \\
Total & 25.85 & 28.16 & 37.41 \\
\hline
\end{tabular}

Table 11. The overall concentration results after the attrition scrubbing/classification scheme and the Falcon processing of the fines

\begin{tabular}{llll}
\hline Product & Wt., $\%$ & $\mathrm{P}_{2} \mathrm{O}_{5} \%$ & $\mathrm{P}_{2} \mathrm{O}_{5}$ Dist., $\%$ \\
\hline Attrition concentrate $(-2.30+0.071 \mathrm{~mm})$ & 35.06 & 28.72 & 51.75 \\
$-0.071 \mathrm{~mm}$ phosphomud concentrate & 25.85 & 28.16 & 37.41 \\
Total & 60.91 & 28.48 & 89.16 \\
\hline
\end{tabular}

\section{Conclusion}

It could be concluded that the superfine and ultrafine phosphate of a phosphomud produced after the processing of an East Mediterranean phosphate ore containing $14.73 \% \mathrm{P}_{2} \mathrm{O}_{5}, 15.03 \%$ acid insoluble, and $19.07 \%$ loss in ignition, were recovered using the Falcon Concentrator model SB40-VFD (semi-continuous with variable frequency drive) with a grade and $\mathrm{P}_{2} \mathrm{O}_{5}$ recovery reaching $28.29 \%$, and $95.97 \%$, respectively, in case of separating the overall fines sample as one feed. In case of the fractionated feeding samples as $-32+11$ micron and -11 micron size fractions, the global grade and recovery reached $29.21 \%$, and $88.42 \%$, respectively.

The application of the CCRD that modeled and optimized the -11 micron fraction separation showed that the calculated predicted values of the two responses, grade and recovery were in a good agreement with the experimental values $\left(\mathrm{R}^{2}=0.99\right.$ for both responses). In addition, the bowl rotation frequency showed to have the main irreversible effect on the product grade, whereas the fluidizing water pressure had the main reversible effect on the recovery. On the other hand, the feeding rate showed some effect on the product grade with almost no effect on its $\mathrm{P}_{2} \mathrm{O}_{5}$ recovery\%.

The statistical optimization conditions of the Falcon Concentrator separation of -11 micron size fraction stated that the optimum recovery conditions are $70-75 \mathrm{~Hz}$ rotation frequency and $2-4 \mathrm{psi}$ water pressure at a feeding rate of $6.47 \mathrm{~g} / \mathrm{min}$. By adding the results achieved in Part One dealing with the $+0.075 \mathrm{~mm}$ fraction, the global $\mathrm{P}_{2} \mathrm{O}_{5}$ 
recovery will reach about $89 \%$. These results confirm the validity of the process to make use of slimes instead of sending them to the dump.

\section{Conflict of interests}

The authors declare that there is no conflict of interests regarding the publication of this paper.

\section{References}

Abela, R. L. (1997). Centrifugal concentrators in gold recovery and coal processing. Extraction Metallurgy Africa. 25-26 June Johannesburg.

Al-Bassam, K. S., Aba-Hussain, A. A., Mohamed, I. Q., \& Al-Rawi, Y. T. (2010). Petrographic classification of phosphate components of East Mediterranian phosphorite deposits. Iraqi Bulletin of Geology and Mining, 6, 59-79.

Ancia, P. H., Frenay, J., \& Dandois, P. H. (1997). Comparison of the Knelson and Falcon centrifugal separators. In: Richard M. Mozley International Symposium.

Bradley, P., Patil, D. P., \& HO, K. (2000). Development and demonstration of an enhanced gravity separator for coal cleaning. Technical Report, Illinois Clean Coal Institute.

Chen, M., \& Graedel T. E. (2016). A half-century of global phosphorus flows, stocks, production, consumption, recycling, and environmental impacts. Global Environmental Change, 36, 139-152.

Cordell, D., \& White, S. (2015). Tracking phosphorus security: indicators of phosphorus vulnerability in the global food system. Food Security, 7, 337-350

Deveau, C. (2006). Improving fine particle gravity recovery through equipment behavior modification. 38th Annual Meeting of the Canadian Mineral Processors, paper 31, 501-517.

El-Midany, A. A., \& Ibrahim, S. S. (2011). Does calcite content affect its separation from celestite by Falcon concentrator. Powder Technology, 213, 41-47.

Freire, L. A., Leite, J. Y. P., da Silva, D. N., da Silva, B. G., \& Oliveira, J. C. S. (2019). Behavior of the chromite tailings in a centrifugal concentrator (FALCON). REM, Int. Eng. J., Ouro Preto, 72, 147-152.

Geissler, B., Mew, M. C., Weber, O., \& Steiner, G. (2015). Efficiency performance of the world's leading corporations in phosphate rock mining. Resources, Conservation and Recycling, 105(Part B), 246-258.

Holtham, P., Gee, B., Dunne, R., \& Gregory, S. (2005). Recovery of fine gold particles using a Falcon 'B' separator. In G. Deschenes (Ed.), International Symposium for the Treatment of Gold Ores. Calgary, Alberta, Canada.

Honaker, R. Q., Paul, B. C., Wang, D., \& Huang, M. (1994). Application of centrifugal washing for fine coal cleaning. Society for Mining, Metallurgy and Exploration Annual Meeting.

Honaker, R. Q., Wang, D., \& Ho, K. (1996). Application of the Falcon concentrator for fine coal cleaning. Minerals Engineering, 9, 1143-1156.

Ibrahim, S. S., Yassin, K. E., \& Boulos, T. R. (2019). Processing of an East Mediterranean phosphate ore sample by an integrated attrition scrubbing/classification scheme (Part One). Separation Science and Technology.

Jean-Sébastien, K. R., Bourgeois, F., \& Climent, E. (2009). Fluid dynamics based modelling of the Falcon concentrator for ultrafine particle beneficiation. Minerals Engineering, 23, 313- 320.

Kademli, M. M., \& Aydogan, N. A. (2019). An extraction of copper from recycling plant slag by using falcon concentrator. Mineral Resources Management, 35, 117-128.

Kohmuench, J. (2003). Demonstration of a phosphate recovery circuit for existing waste streams. American Seed Fund, Contract DE-FG02-03ER83650.

Laplante, A. R., \& Nickoletopoulos, N. (1997). Validation of a Falcon model with a synthetic ore. Canadian Metallurgical Quarterly, 36, 7-13.

Laplante, A. R., \& Shu, Y. (1993). A comparative study of two centrifugal concentrators. 25th Annual Meeting of the Canadian Minerals Processors, Paper 5, 18-36.

Laplante, A. R., Buonvino, M., Veltmeyer, A., Robitaille, J., \& Naud, G. (1994). A study of the Falcon concentrator. Canadian Metallurgical Quarterly, 33, 279- 288.

Luttrell, H., Honaker, Q., \& Phillips, I. (1995). Enhanced gravity separators: New alternatives for fine coal cleaning. 12th International Coal Preperation Congress, Lexington, Kentucky. 
Majumder, A. K., Lyman, G. J., Brennan, M., \& Holtham, P. N. (2006). Modeling of flowing film concentrators part 1. water split behavior. International Journal of Mineral Processing, 80, 71-77.

McAlister, S. A., \& Armstrong, K. C. (1998). Development of the Falcon concentrator. Society for Mining, Metallurgy and Exploration Annual Meeting, 172, 98-230. Orlando; FL; USA. Publisher: SME.

Mew, M. C. (2016). Phosphate rock costs, prices and resources interaction. Science of the Total Environment, 542, 1008-1012.

Negm, A. A., \& Abouzeid, A. Z. M. (2008). Utilization of solid wastes from phosphate processing plants. Physicochemical Problems of Mineral Processing, 42, 5-16.

Özgen, S. (2017). Purification with Falcon gravity concentrator processing of low-grade bentonites and modeling. Particulate Science and Technology, 35, 346-354.

Rath, R. K., \& Singh, R. (2007). Gravity concentration of iron ores. Chapter Seven, PIO, 78-88.

Rath, R. K., Dey, B., Mohanta, M. K., Prusty, L. K., \& Singh, R. (2017). Recovery of chromite values from tailings of COB plant using enhanced gravity concentrator. In: International Conference on Mineral Processing Technology (MPT-2017). Mahabalipuram, Chennai.

Teague, A. J., \& Lollback, M. C. (2012). The beneficiation of ultrafine phosphate. Minerals Engineering, 27-28, 52-59.

\section{Copyrights}

Copyright for this article is retained by the author(s), with first publication rights granted to the journal.

This is an open-access article distributed under the terms and conditions of the Creative Commons Attribution license (http://creativecommons.org/licenses/by/4.0/). 